\title{
Subfoveal choroidal thickness in polypoidal choroidal vasculopathy after switching to intravitreal aflibercept injection
}

\author{
The Editors, Japanese Journal of Ophthalmology ${ }^{1}$
}

Received: 9 April 2016/Accepted: 1 July 2016/Published online: 5 October 2016

(C) Japanese Ophthalmological Society 2016

\section{To the Editor,}

We have read and reviewed the article entitled as "Subfoveal choroidal thickness in polypoidal choroidal vasculopathy after switching to intravitreal aflibercept injection" by Saito et al. with interest [1]. The authors state that the choroidal thickness (CT) significantly decreased after switching to intravitreal aflibercept injection in eyes with polypoidal choroidal vasculopathy (PCV) refractory to ranibizumab. Intravitreal aflibercept $(2 \mathrm{mg} / 0.05 \mathrm{ml})$ injections were administered for three consecutive months, including a loading dose followed by further injections in the following 2 months. The authors found significant reductions in subfoveal CT (from 203 to $171 \mu \mathrm{m}$ ), and in central retinal thickness (from 249 to $161 \mu \mathrm{m}$ ) at month 6 . We would like to ask for further details, and contribute to the article.

We wonder whether the authors considered some additional important parameters when obtaining optical coherence tomography (OCT) measurements. Of note, CT has a significant diurnal variation $[2,3,4]$. The choroid could increase its thickness by $50 \%$ in an hour, and quadruple its thickness in a few days [2]. Kee et al. demonstrate that the choroid could thin very rapidly, by about $100 \mu \mathrm{m}$ in 3-4 h in young chicks [3]. Tan et al. measured CT in humans at 2-h intervals between 9:00 AM and 5:00 PM, and determined significant differences in CT among all measurement points [4]. Tan et al. found mean

The Editors, Japanese Journal of Ophthalmology

jjo@po.nichigan.or.jp

1 Tokyo, Japan diurnal amplitude of $\mathrm{CT}$ as $33.7 \pm 21.5 \mu \mathrm{m}$ (range 3-67 $\mu \mathrm{m})$.

Usui et al. evaluated subfoveal choroidal thickness (SFCT) in healthy subjects, and measured SFCT every $3 \mathrm{~h}$ over a 24-h period. In that study, they show that diurnal variations of $\mathrm{CT}$ might be as high as $65 \mu \mathrm{m}$ (range 8-65 $\mu \mathrm{m})$ [5].

Therefore, a significant effect of physiological fluctuation on test measurement results and statistical analyses should be expected when assessing CT measurements. We suggest performing OCT measurements along with preoperative and postoperative follow-up examinations at set times, and at certain time periods of the day.

Additionally, various local or systemic physiological/pathological conditions affect CT [2]. We are curious whether the authors analyzed the participants of this study for systemic diseases, medication history and body mass index, as well as for sleeping and exercise status, consuming alcohol and beverages with or without caffeine before OCT tests. We also wonder what were the systemic blood pressure measurement results.

Finally, the participants of this study are elderly (mean age $75.7 \pm 5.8$ years, range $60-88$ years). Since various systemic or local diseases, and medications may have significant effects on CT, we wonder what were the systemic disease statuses and medication history of the patients [2]. All those factors may significantly have affected the results of the study and statistical analysis. We suggest that the authors should consider and mention all those parameters in the study.

Sincerely,

Salih Uzun, MD

Department of Ophthalmology, Etimesgut Military Hospital, Ankara, Turkey 
Emre Pehlivan, MD

Department of Ophthalmology, Eskisehir Military Hospital, Eskisehir, Turkey

\section{References}

1. Saito M, Kano M, Itagaki K, Ise S, Imaizumi K, Sekiryu T. Subfoveal choroidal thickness in polypoidal choroidal vasculopathy after switching to intravitreal aflibercept injection. Jpn J Ophthalmol. 2016;60: 35-41.

2. Nickla DL, Wallman J. The multifunctional choroid. Prog Retin Eye Res. 2010;29: 144-68.

3. Kee CS, Marzani D, Wallman J. Differences in time course and visual requirements of ocular responses to lenses and diffusers. Invest Ophthalmol Vis Sci. 2001;42:575-83.

4. Tan CS, Ouyang Y, Ruiz H, Sadda SR. Diurnal variation of choroidal thickness in normal, healthy subjects measured by spectral domain optical coherence tomography. Invest Ophthalmol Vis Sci. 2012;53:261-6.

5. Usui S, Ikuno Y, Akiba M, et al. Circadian changes in subfoveal choroidal thickness and the relationship with circulatory factors in healthy subjects. Invest Ophthalmol Vis Sci. 2012;53:2300-7.

\section{Author's Reply}

Many thanks to Drs. Uzun and Pehlivan for showing interest in our paper "Subfoveal choroidal thickness in polypoidal choroidal vasculopathy after switching to intravitreal aflibercept injection" [1] and commenting on it.

We agree that numerous systemic and local factors might influence the choroidal thickness and its changes. Unfortunately, in the current study, systemic diseases, medication history, patient's conditions such as body mass index or sleeping and exercise status, consuming alcohol, beverages with or without caffeine and blood pressure were not evaluated. However, a well-trained investigator examined each patient for these conditions during office hours, which seems to be the standard procedure in clinical studies as evidenced by past reports [2, 3].

Although the subject of diurnal variation in choroidal thickness should be considered, Seidel G et al. report that the macular choroidal volumes remained almost stable during office hours (9 AM to 6 PM) [4]. Therefore, we are convinced that our results of choroidal thickness acceptable values in a clinical study.

Again, we thank the insightful and valuable comments from Drs. Uzun and Pehlivan. While further studies are needed to elucidate the clinical significance of the decreased choroidal thickness after switching to aflibercept therapy in eyes with polypoidal choroidal vasculopathy (PCV), we believe that our paper will help ophthalmologists in treating patients with PCV.

Masaaki Saito, MD

Department of Ophthalmology and Visual Sciences, Akita University Graduate School of Medicine, Akita, Japan

\section{References}

1. Saito M, Kano M, Itagaki K, Ise S, Imaizumi K, Sekiryu T. Subfoveal choroidal thickness in polypoidal choroidal vasculopathy after switching to intravitreal aflibercept injection. Jpn J Ophthalmol. 2016;60:35-41.

2. Koizumi H, Kano M, Yamamoto A, Saito M, Maruko I, Kawasaki R, et al. Short-term changes in choroidal thickness after aflibercept therapy for neovascular agerelated macular degeneration. Am J Ophthalmol 2015;159:627-33e1.

3. Koizumi H, Kano M, Yamamoto A, Saito M, Maruko I, Sekiryu T, et al. Subfoveal choroidal thickness during aflibercept therapy for neovascular age-related macular degeneration: twelve-month results. Ophthalmology 2016;123:617-24.

4. Seidel G, Hausberger S, Herzog SA, Palkovits S, Pöschl EM, Wackernagel W, et al. Circadian macular volume changes in the healthy human choroid. Am J Ophthalmol 2015;159:365-71e2. 